\title{
A Model for Engineering Ethics Education through a Co-op Program
}

\section{Dr. Chris Plouff, Grand Valley State University}

Chris Plouff, Ed.D., P.E., is the Assistant Director of the School of Engineering and the James R. Sebastian Chair of Engineering Cooperative Education and Educational Development at Grand Valley State University. He is an Assistant Professor and coordinates assessment efforts for the School of Engineering, including for the mandatory cooperative education program. His research interests include effective assessment of engineering education, cooperative education, transition to and from the engineering educational environment, and first-year engineering program development. Prof. Plouff has a Doctorate in Education from Eastern Michigan University, a Master's degree in Environmental Engineering from Michigan Tech University, and is a registered Professional Engineer in Michigan.

\section{Dr. Nael Barakat, Grand Valley State University}

Dr. Nael Barakat is a professor of Mechanical Engineering (ME) at Grand Valley State University (GVSU), Grand Rapids, MI. He is a registered professional engineer in Ontario, Canada, and a fellow of the American Society of Mechanical Engineers (ASME). His areas of interest include Controls, Robotics, Automation, Systems dynamics and Integration, Metrology, NEMS, as well as Engineering Ethics, professionalism, and Education. Dr. Barakat is currently the chair of the Technology and Society (T \& S) Division and the ASME district B leader. He is the current secretary/treasurer of the ASEE Ethics Division. 


\title{
A Model for Engineering Ethics Education Leveraging Workplace Experiences through a Co-op Program
}

\begin{abstract}
Educating engineering student about professional ethics involves multiple challenges. These challenges can be extrinsic such as finding a proper place, timing, and quantity for this topic in the curriculum to provide to engineering students. These challenges can also be intrinsic including finding the appropriate method of delivery of this topic as well as the proper hands-on experiences or context to support this knowledge, particularly in engineering where students are trained on combining theory with practice.

Many models have been proposed in the literature to educate engineering students about professional ethics. This paper presents a model that infuses ethics education across three years of the engineering program by delivering a scaffolded curriculum, using both classroom and online distance education methodologies. The framework for the model is situated within the structure of the mandatory cooperative education program. Ethics instruction occurs during a required cooperative education preparatory course, as well as during each of three semesters when students are employed with industry partners to practice engineering in a cooperative education program.
\end{abstract}

Introductory engineering ethics content is provided in the preparatory course, including review and assessment of case studies. During the co-op work semesters, online tools have been developed that allow for easy collection and summarization of input related to student outcomes. Students are required to complete online, distance-learning modules during each cooperative education semester which allow for additional direct measurement of student learning outcomes, including five engineering ethics-focused modules. The cooperative education program provides assessment of students learning outcomes on a continuous (every semester), annual basis. The framework for assessment and assessment plans will be detailed, and example outcomes will be shared to demonstrate how this information is evaluated and used for curricular improvement. In addition, employer evaluations during the co-op semesters provide input on student abilities related to ethical behavior in the workplace.

Outcomes of the continuous assessment and improvement of this program over the pilot trial, as well as full implementation with modifications learned from the pilot trial over two following classes of engineering students, are reported and discussed. Results show that students' perceptions, the timing of the content delivery, and context, play a significant role in the effectiveness of this delivery model. Initial results indicate that students are demonstrating mastery of applied ethics-based knowledge and abilities between beginner and intermediate levels by the end of the cooperative education program.

Introduction

Demonstration that graduates of an engineering program have met student learning outcomes is required to be compliant with ABET expectations for accreditation. Professional skills constitute a significant part of these learning outcomes. ${ }^{[1]}$ There are many ways to demonstrate mastery of 
these learning outcomes. Most commonly, this is accomplished through assessment of some course-related activity including homework assignments, exams, laboratories, and projects. However, some of the learning outcomes are not easy to assess in a typical classroom setting. In particular, professional skills and their related outcomes are the most challenging to assess, like student learning outcome ' $\mathrm{f}$ ' which states that by the time a student graduates, they must have an understanding of the professional and ethical responsibility. ${ }^{[1]}$ Multiple challenges have been reported in the literature regarding educating students, and assessing the mastery level of this particular outcome. ${ }^{[2,3]}$ Some of these challenges are common to all engineering programs, including limitations to adding new content, and the nature of these skills not stemming from fundamental math and science concepts. ${ }^{[4]}$ In general, finding a balance between the content, the delivery format, the time of delivery, and the location in the curriculum for this material constitutes a significant challenge in engineering education. ${ }^{[5]}$

Therefore, alternative venues have been tried and proven helpful in demonstrating these learning outcomes. Also, faculty are often the sole assessors of the student learning outcomes in classroom settings, and including input from other qualified constituents as part of the assessment process can result in a more robust and quality process. Internship and co-op programs provide a unique opportunity to have students engage in learning professional skills, including engineering ethics, in an environment different than the classroom. It also provides a medium for students to work with, and be assessed by, practicing engineers, in the workplace. These types of programs provide an external constituent perspective and input to the assessment process, which improves the overall process.

Grand Valley State University (GVSU) has developed a comprehensive, scaffolded approach to delivering engineering ethics instruction and providing applied experiences that is centered on the mandatory co-op program. This paper describes the academic and assessment programs at GVSU related to ABET learning outcome 'f,' and provides examples of how the co-op program is central to those efforts. In addition, the use of the co-op program as the primary vehicle for assessment of this learning outcome provides the additional benefits of curriculum and assessment input by industry constituents who work directly with the students.

\section{Curriculum Overview}

The School of Engineering at GVSU offers a bachelor of science in engineering degree with majors in computer, electrical, interdisciplinary, product design and manufacturing, and mechanical engineering. The majors share a mostly common set of foundation courses, and each undergraduate major is a secondary admission program. Criteria for secondary admission include completion of all foundation courses with a grade of ' $\mathrm{C}$ ' or better and maintaining an overall grade point average of 2.70 or higher (on a 4.00 scale).

All programs are accredited as co-op programs through ABET. Prior to the start of the co-op semesters, all students take a cooperative education preparatory course. During the co-op component of the program, the student alternates semesters of academic, on-campus coursework with semesters of practice-oriented work hosted by a workplace with engineering-related functions. The academic semesters include the upper-division coursework for each major. 


\section{Co-op Program Overview}

All admitted undergraduate students participate in a mandatory co-op program, for a total of twelve months of work experience, during the junior and senior year of the academic program. The cooperative education program is an alternating semester program that the student participates in during the last two years of the academic curriculum after secondary admission. Students work with the same company/organization for each of three four-month-long semesters. A typical sequence for a student is shown in Table 1.

Table 1: Academic/Co-op Sequence at GVSU

\begin{tabular}{|c|c|c|c|}
\hline & Fall & Winter & Spring/Summer \\
\hline Year 1 & (Sept.-Dec.) & (Jan.-April) & (May-Aug.) \\
\hline Year 2 & & & \\
\hline Year 3 & & Co-op II & Co-op I \\
\hline Year 4 & Co-op III & & \\
\hline & & & \\
\hline & = Engineering Fundamentals Coursework \\
\hline & \multicolumn{3}{|c|}{ = Engineering Upper Division Coursework } \\
\hline
\end{tabular}

Students receive three credits for each semester of co-op, for a total of nine co-op credits applied towards graduation. The student receives a letter grade for each co-op semester which is determined by taking into account the evaluations provided by the work supervisor, and the accuracy and quality of written work. A faculty member monitors and assesses the work of the student in collaboration with the co-op supervisor, including review of weekly student journals and visiting the work site each semester. At the end of every co-op semester, each student is assessed by the company supervisor using an online data collection tool. The assessment tool includes questions that are directly mapped to each of the program student learning outcomes. In addition, a faculty member is assigned as an advisor to each student during the co-op semesters. The faculty member corresponds on a regular basis throughout the semester with the student, and visits the worksite to meet with the student and supervisor to review the student's work. This process provides two points for assessing the program student learning outcomes for each student.

Additional educational material is covered using modules via distance-learning. These modules target the coverage of professional skills and knowledge that engineering students need but do not easily get from on-campus, traditional technical courses. The content of the modules include material on engineering ethics and professionalism, engineering economy, project management, entrepreneurism, and professional communication. The complete set of on-line modules constitutes a thread of three full courses that are divided over the three required co-op courses. 
Having exposure to these practice-related issues while being in the workplace presents a unique opportunity for the students to apply what is learned. ${ }^{[6]}$

Modules are designed to be relatively brief, focused packets of information that could be reviewed within a 30-60 minute timeframe. The modules are delivered via Blackboard, the university-wide, web-based course management software, and consist of various media including written materials, papers, videos, websites, podcasts, etc. Each module has an associated, short test or quiz that is automatically graded in Blackboard. Students have six to eight modules to complete in a given co-op semester, which is almost equivalent of one lecture-course credit. Modules are 'open' at scheduled times throughout the semester and students are required to complete them during that timeframe. A primary instructor is available for discussion and to answer questions at both regularly scheduled times for phone or video chat, as well as via email, chat or discussion board.

Internet based programs focusing on learning professional skills, within engineering, have been around for a while. ${ }^{[7]}$ On-line education has long been reported advantageous in handling large numbers of students for efficient delivery. This is an added advantage with the current academic content delivery during the co-op program at GVSU.

Ethics Curriculum

Students are first introduced to a concept of ethics in the first year of the engineering curriculum. During the first engineering course, students are provided with the School of Engineering Honor Code, asked to read it, and sign a copy to be kept as part of their student record. The Honor Code states:

An engineering student will not lie, cheat, or steal, or tolerate those who do. Rules of thumb:

- Does this action attempt to deceive anyone or allow anyone to be deceived? Handing in or using someone else's work in electronic or any other form is deceiving my instructor. Grades are assigned to assess my grasp of a concept or skill for future use. If I choose to evade the evaluation or grading process in this way I will deceive my instructor, but I will also deceive my future employer, the clients who will depend on my engineering expertise, and the general public.

- Does this action result in an undue advantage to which I would otherwise not be entitled?

- Would I be satisfied by the outcome if I were on the receiving end of this action?

This honor code is written in a simplified language for better comprehension by freshman students and to raise their awareness of the issue directly related to their everyday work and environment. As students advance in the school of engineering and develop sufficient maturity, a more comprehensive content on ethics is provided to them. The core of the ethics curriculum in the School of Engineering at GVSU is centered in the mandatory cooperative education program. Engineering ethics is introduced in the co-op preparatory course (EGR 289) and then further explored and reinforced in the three co-op semesters (EGR 290, EGR 390 and EGR 490). The assessment of the ethics outcome occurs in the co-op program courses. 
The purpose of the co-op preparatory course is to get students ready for the mandatory co-op program, including job search preparation and helping students become knowledgeable of engineering workplace structures and operations. This content includes introduction, discussion and application of engineering ethics. The material focuses on basic definitions and concepts related to ethics, codes of ethics, the School of Engineering Honor Code, whistleblowing, ethics in the job search process, and steps for addressing an ethical issue in the workplace. The discussion and application includes review and discussion of case studies that have students explore issues related to ethics in academics (e.g. cheating on a test) and simple issues that might confront students during their first co-op semesters (e.g. keeping ones word when accepting a coop position, and reporting of work time on time cards).

Students are given a written assignment to review a case study and provide analysis of the case based on the classroom discussion materials. The recent case studies which have been used include the Therac- 25 case $^{[8]}$ and the Ruskin Manufacturing case - titled 'Shortage of Components ${ }^{[9]}$ from the National Academy of Engineering's Online Ethics Center website. Students are asked to prepare a one-page memo responding to the case study, discussing the following items:

1. Identify the ethical issues in the case study.

2. How can ethical standards or codes from the profession of engineering be applied to the case study?

3. Identify specific items within the code(s) that relate to issues in the case study

4. Propose appropriate actions that should have been taken by the people involved in the case study, taking into account the ethical standards of our profession.

During the co-op semesters, while the students are in the workplace, students are provided with online educational content, facilitated by a faculty member. The content of the online module curriculum for the engineering ethics instruction is shown in Table 2. Students review written materials provided through the Blackboard course management software, interface with the faculty member for clarification and questions, and take a quiz to demonstrate mastery of the content.

A key advantage to focusing on the ethics instruction during the co-op program is the opportunity for students to apply concepts in the workplace, while practicing engineering. This is ideal since engineering ethics by definition is a type of applied ethics, and learning about ethics while 'doing' engineering is important to understanding how to apply the concepts in real situations. Not unlike having an engineering design course without a hands-on project or lab component to practice and apply the theoretical concepts, teaching engineering ethics from a purely theoretical vantage point leaves students without the experience of 'doing' that is needed for engineering education. ${ }^{[10]}$ Interesting observations were collected directly from students, as well as from their journals, and their interactions during co-op with their co-workers, in application to the concepts of ethics. One extreme reaction from one student was a remark provided to the supervising faculty regarding some actions by the employer which raised the student's suspicions of the existence of some unethical behavior. The students wrote the note with reference to concepts and parts of a professional code of ethics. This was an invaluable 
Table 2: Online Academic Ethics Curriculum

\begin{tabular}{|c|}
\hline Co-op I \\
\hline - personal vs. professional ethics \\
\hline - engineering as a profession \\
\hline - understanding codes of ethics \\
\hline - connection of ethical problem solving to engineering design \\
\hline - professional responsibility and legal liability \\
\hline - legal responsibility of engineering \\
\hline Co-op II \\
\hline - ethical theories \\
\hline - application concepts of ethical theories \\
\hline - analyzing and solving ethical problems \\
\hline - honesty and integrity \\
\hline - academic and professional dishonesty \\
\hline - conflict of interest \\
\hline Co-op III \\
\hline - engineering ethics and the environment \\
\hline - sustainable development \\
\hline
\end{tabular}

opportunity to educate and guide the student through handling the situation professionally, without causing any undesirable outcomes, to correct the situation.

\section{Programmatic and Co-op Assessment}

Each major in the School of Engineering has a comprehensive assessment and evaluation plan for reviewing appropriate and effective mastery of student learning outcomes. The plan is a multi-tiered approach that includes input from all major constituents to the program including faculty, students, employers, alumni, and community members. Specific assessment and evaluation processes that are used for the ethics curriculum include:

- Course assessment of student work during the co-op preparatory course. This course is offered once per year, and student learning outcome assessment occurs on a biennial basis, with the most recent assessment occurring in Fall 2012.

- Couse assessment of student work during the co-op semesters (online modules). Co-op semesters occur every semester (fall, winter, and summer), with the most common semester for EGR 290 - Co-op I being summer, for EGR 390 - Co-op II being winter, and EGR 490 - Co-op III being fall. Student learning outcome assessment occurs on a biennial basis, with the most recent assessment occurring in Fall 2013.

- Employer assessment of student work during co-op work semesters (three assessments for each student - one for each co-op semester). A group of students is on co-op every semester, and therefore employer feedback is received every semester. Co-op assessments of students contain performance criteria related to achievement of every student learning outcome.

- Senior exit surveys are conducted for the graduating seniors each summer. In the survey, seniors are asked about the engineering ethics instruction as part of the curriculum. 


\section{Ethics Outcomes Assessment Results and Discussion}

The following results related to engineering ethics education for the years 2012 and 2013 are summarized and discussed: 1) co-op preparatory course outcomes, 2) co-op semester online modules outcomes, 3) employer assessments of co-op students, and 4) senior exit survey results.

The papers written in the co-op preparatory course reflecting on the ethics case studies were summarized and assessed for the Fall 2012 semester. There were 114 students in the course (3 sections of the course were offered), and students wrote the memo reflecting on the Therac- 25 case study. There were 72 student work samples assessed, and the mean score was a 3.19 (on a 4.00 scale), with a standard deviation of 0.66 . The target score for the assessment was a 3.00 (equivalent to a $75 \%$ score). Students did a good job of identifying the ethical issues in the case study and, for the most part, connecting them to engineering practice. While the students scored well overall on the content of ethics and met the target, students did not do as good of a job at connecting the ethical issues directly to any professional codes of ethics. Students either did well in connecting to professional codes or did not - there was little in between. It was recommended that more time should be spent on reviewing specific codes of ethics within the profession and demonstrating how to use them and connect them to engineering practice. To this end, an additional, dedicated class session was created for the Fall 2013 semester to address ethics and engineering codes of ethics.

Table 3 provides the results of the quizzes on ethics instruction as part of the online curriculum used during the co-op semesters in the 2012 and 2013 years. The target scores for the quizzes was a $75.0 \%$. As seen in Table 3, students performed at or above the target level, on average, for all quizzes except the quizzes for Module 2 in the first co-op semester (EGR 290). The reason that the quiz scores have been lower for Module 2 is because the content of that module was intentionally written at a more advanced level, including the application of the content in the quiz questions. This was done to provide a check with the target level of the material as well as the student attention and effort to the online material. It is evident after two offerings of the module and associated quiz that students both have not mastered the material at an appropriate level. This is likely due to the advanced nature of the material and application-level on the quiz, as well as potentially over confidence of the student in taking the quiz after performing well on the quiz for Module 1. The target level of the material and application on the quiz will be appropriately adjusted for the Summer 2014 offering of the course.

Table 4 provides the summarized outcomes of the employer evaluations at the end of the stated co-op course and semester. A question on the evaluation states, "The student assumes responsibility in a trustworthy manner," then asking the employer to rate the student's performance accordingly. This question relates to the student's professionalism and whether they have performed in an ethical manner during their work assignments. The target score was 3.00 (on a 4.00 scale) - equivalent to a $75 \%$ score. It is evident that employers thought students 
Table 3: Co-op Semester Ethics Modules Quiz Results (on a 100-point scale)

\begin{tabular}{|c|c|c|c|}
\hline \multicolumn{1}{|c|}{ Co-op Semester } & n & Mean & $\begin{array}{c}\text { Standard } \\
\text { Deviation }\end{array}$ \\
\hline EGR 290 - Co-op I & & & \\
\hline Module 1 & & & \\
\hline Summer 2013 & 83 & 89.4 & 13.4 \\
\hline Summer 2012 & 58 & 84.3 & 17.3 \\
\hline Summer 2013 & 80 & 63.6 & 14.6 \\
\hline Summer 2012 & 56 & 58.9 & 16.3 \\
\hline EGR 390-Co-op II & & & \\
\hline Module 3 & & & \\
\hline Winter 2013 & 58 & 79.1 & 14.4 \\
\hline Winter 2012 & 62 & 71.0 & 18.5 \\
\hline Winter 2013 & 47 & 83.8 & 17.0 \\
\hline Winter 2012 & 54 & 83.7 & 12.2 \\
\hline EGR 490-Co-op III & & & \\
\hline Module 5 & & & \\
\hline Fall 2013 & 55 & 74.3 & 15.1 \\
\hline Fall 2012 & 65 & 76.0 & 17.3 \\
\hline
\end{tabular}

performed well in this area in the workplace with mean scores typically at a score of 3.50 or higher over a two-year period. There was only one employer rating that was at a level lower than 'agree' over the course of the two years of feedback, indicating that students conducted themselves in an ethical manner in the workplace.

The final piece of assessment data reviewed was the feedback provided by students when they graduated, as part of a senior exit survey. Students were given the statement "My GVSU education prepared me to deal with ethical dilemmas in my co-op or professional work/environments" and asked to provide a rating of their level of agreement with the statement. The scores used a 4.00 scale, and as with the prior assessments, the target score was 3.00. As seen in Table 5, the scores over the past two years have been, on average, right at 3.00 for two majors and just below 
Table 4: Employer Evaluation of Student after Co-op Semester - question asked "The student assumes responsibility in a trustworthy manner"

\begin{tabular}{|c|c|c|c|c|c|}
\hline Major/Co-op Course & $\begin{array}{c}\text { Strongly } \\
\text { Disagree } \\
\text { (1) }\end{array}$ & $\begin{array}{c}\text { Disagree } \\
\text { (2) }\end{array}$ & $\begin{array}{c}\text { Agree } \\
\text { (3) }\end{array}$ & $\begin{array}{c}\text { Strongly } \\
\text { Agree } \\
\text { (4) }\end{array}$ & $\begin{array}{l}\text { Mean Score } \\
\text { (4-point scale) }\end{array}$ \\
\hline \multicolumn{6}{|l|}{ Computer Engineering } \\
\hline EGR 290 Co-op I (Summer 2013) & 0 & 0 & 2 & 7 & 3.78 \\
\hline EGR 390 Co-op II (Winter 2012) & 0 & 0 & 3 & 9 & 3.75 \\
\hline EGR 490 Co-op III (Fall 2013) & 0 & 0 & 0 & 5 & 4.00 \\
\hline Mean: & 0 & 0 & 5 & 21 & 3.81 \\
\hline \multicolumn{6}{|l|}{ Electrical Engineering } \\
\hline EGR 290 Co-op I (Summer 2013) & 0 & 0 & 6 & 8 & 3.57 \\
\hline EGR 390 Co-op II (Winter 2012) & 0 & 1 & 4 & 9 & 3.57 \\
\hline EGR 490 Co-op III (Fall 2013) & 0 & 0 & 3 & 9 & 3.75 \\
\hline Mean: & 0 & 1 & 13 & 26 & 3.62 \\
\hline \multicolumn{6}{|l|}{ Mechanical Engineering } \\
\hline EGR 290 Co-op I (Summer 2013) & 0 & 0 & 19 & 29 & 3.60 \\
\hline EGR 390 Co-op II (Winter 2012) & 0 & 0 & 16 & 9 & 3.36 \\
\hline EGR 490 Co-op III (Fall 2013) & 0 & 0 & 6 & 13 & 3.68 \\
\hline Mean: & 0 & 0 & 41 & 51 & 3.55 \\
\hline \multicolumn{6}{|l|}{$\begin{array}{l}\text { Product Design \& Manufacturing } \\
\text { Engineering }\end{array}$} \\
\hline EGR 290 Co-op I (Summer 2013) & 0 & 0 & 3 & 8 & 3.73 \\
\hline EGR 390 Co-op II (Winter 2012) & 0 & 0 & 6 & 3 & 3.33 \\
\hline EGR 490 Co-op III (Fall 2013) & 0 & 0 & 3 & 6 & 3.67 \\
\hline Mean: & 0 & 0 & 12 & 17 & 3.59 \\
\hline
\end{tabular}

for two others. From the graduating student perspective, they are adequately prepared for dealing with ethical issues in their early career. As is typical with many self-assessments, students may tend to score themselves lower than their actual knowledge and skills level, as evidenced by scores on the course assessments and feedback from employers on the students' actual performance in the area of ethical behavior.

In general, the approach used to deliver and assess engineering ethics to student in the School of Engineering at GVSU consists of a scaffolded method where content is delivered in multiple format at different levels of students' academic maturity. Assessment is conducted frequently and results are collected from multiple sources to provide better insight into students' learning and the effectiveness of this delivery method. 
Table 5: Senior Exit Survey Results - question asked "My GVSU education prepared me to deal with ethical dilemmas in my co-op or professional work/environments"

\begin{tabular}{|c|c|c|c|c|c|}
\hline Major/Graduation Year & $\begin{array}{c}\text { Strongly } \\
\text { Disagree } \\
(\mathbf{1})\end{array}$ & $\begin{array}{c}\text { Disagree } \\
(\mathbf{2})\end{array}$ & $\begin{array}{c}\text { Agree } \\
\mathbf{( 3 )}\end{array}$ & $\begin{array}{c}\text { Strongly } \\
\text { Agree } \\
\mathbf{4}\end{array}$ & $\begin{array}{c}\text { Mean Score } \\
\text { (4-point scale) }\end{array}$ \\
\hline Computer Engineering & & & & & \\
\hline Summer 2013 & 1 & 0 & 4 & 2 & 3.00 \\
\hline Summer 2012 & 0 & 0 & 5 & 1 & 3.17 \\
\hline Electrical Engineering & & & & & \\
\hline Summer 2013 & 1 & 1 & 6 & 1 & 2.78 \\
\hline Summer 2012 & 0 & 0 & 4 & 0 & 3.00 \\
\hline Mechanical Engineering & & & & & \\
\hline Summer 2013 & 0 & 1 & 13 & 2 & 3.06 \\
\hline Summer 2012 & 0 & 8 & 23 & 1 & 2.78 \\
\hline $\begin{array}{l}\text { Product Design \& Manufacturing } \\
\text { Engineering }\end{array}$ & & & & & \\
\hline Summer 2013 & 0 & 0 & 6 & 1 & 3.14 \\
\hline Summer 2012 & 0 & 2 & 7 & 1 & 2.90 \\
\hline
\end{tabular}

\section{Conclusion}

A curriculum for engineering ethics instruction has been presented that is situated within the framework of a cooperative education program. Including engineering ethics instruction as part of the cooperative education program provides both a unique and beneficial approach to the educational process. Students are able to obtain and apply knowledge and skills in ethical decision making and problem solving while working in an engineering environment, providing real-world opportunities to witness and practice what is learned. The method of using distance education instruction during the co-op semesters appears to work well and provides students with just-in-time education that benefits them while applying their engineering knowledge in the workplace. This model will be expanded in the future to include workplace case studies developed by the students during the co-op semester so that students not only learn about the information related to engineering ethics, but also apply it by reflecting on their own experiences, thereby advancing their knowledge, skills and abilities in ethical decision making.

\section{References:}

[1] 2013 - 2014 Criteria for Accrediting Engineering Programs, Engineering Accreditation Commission of ABET, ABET Inc. Baltimore, MD. www.ABET.org, Retrieved Nov. 2013.

[2] L.J. Shuman, M. Besterfield-Sacre, and J. McGourty, “The ABET 'professional skills' - can they be taught? Can they be assessed?" Journal of Engineering Eduction, vol. 94, no. 1, pp. 41-55, January 2005.

[3] Suk Meng Goh, "Star Power for teaching professional skills to engineering students," Advances in Engineering Education, Vol. 03, issue 01, Winter 2012.

[4] N. Andersson and P. Andersson, "Teaching Professional Engineering Skills - Industry Participation In Realistic Role Play Simulation," Proceedings of the 6th International CDIO Conference, École Polytechnique, Montréal, June 15-18, 2010. 
[5] J. Walther, N. Kellam, N. Sochacka, and D. Radcliffe, "Engineering competence? An interpretive investigation of engineering students' professional formation," Journal of Engineering Eduction, vol. 100, no. 4, pp. 703-740, October 2011.

[6] Plouff C. and N. Barakat, "Infusion of ABET-specified Professional and Academic Content into Off-campus Work Experiences via Distance Learning Modules," Frontiers in Education, Seattle, WA. Sep. 2012.

[7] J. Bourne, D. Harris, and F. Mayadas, “Online engineering education: learning anywhere, anytime," Journal of Engineering Eduction, vol. 94, no. 1, pp. 131-146, January 2005.

[8] Therac-25 Case Study. Online Ethics Center, National Academy of Engineering. http://www.onlineethics.org/cms/4661.aspx, Retrieved Nov. 2013.

[9] Ruskin Manufacturing Case Study. Online Ethics Center, National Academy of Engineering. http://onlineethics.org/Resources/Cases/Shortage.aspx, Retrieved Nov. 2013.

[10] Nael Barakat, "Engineering Ethics: A Critical Dimension of the Profession," International Journal of Engineering Pedagogy (iJEP), Vol. 1, issue 2, July, 2011, www.i-JEP.org, www.online-journals.org, DOI:10.3991/ijep.v1i2.1639 